\title{
Relationship between Anti-frozen Durability and Pore Structure on Concrete in Freeze and Thaw Cycle Environment
}

\author{
Chao Wang, ${ }^{1, *}$ Zhao-Lei $\mathrm{Liu}^{2}$, Lei $\mathrm{Yu}^{2}$ \\ ${ }^{1}$ Guangdong Road and Bridge Construction Development Co. LTD. No.445, Tian Run Road, Tian-he District, Guangzhou City, \\ Guangdong Province, China. \\ ${ }^{2}$ Beijing Xin-Qiao Technology Development Co. LTD. No.8 yard, Xi Tu Cheng Road, Hai-dian District, Beijing, China
}

\begin{abstract}
To detect which micro structure index can make an effected on the anti-frozen durability on concrete, 3 kinds of concrete with different mix proportion have been made. The dynamic modulus of elasticity and pore structure index were detected and the relativity of them was analysed. The result shows that the dynamic modulus of elasticity decreases after freezing and wary with porosity. Critical pore size becomes larger. The gel pore amount decreases. The capillary and macro pore amount increase. There is a good relativity between frost-resistance performance and pore parameters. By decreasing porosity and the amount of macro pore, increasing gel pore amount, the anti-frozen durability can be enhanced.
\end{abstract}

\section{Introduction}

According to China Highway Natural Division [1], two thirds areas of China locate on places where the freeze and thaw situations appear sometimes. The concrete structure in these areas can be affected by freeze and thaw cycle [2]. This can lead to concrete surface peeling off or become unconsolidated [3].

There are some papers to find the mechanism of concrete frost heave and conclude it as the inducement of concrete macro performance decrease[4][5]. But there is rarely study on how to estimate. There is lack of method and result to estimate the frost heave. But, there should be a relationship between macro and micro performance [6].

Therefore, finding the quantization relationship to estimate the degree of macro performance decrease by micro structure change is necessary. So that, the macro performance of concrete can be changed by optimizing the pore structure.

\section{Test plan}

\subsection{Raw materials}

The raw materials include the P.O 42.5 cement, fly ash I, nature sand with medium sand, $5-15 \mathrm{~mm}$ coarse aggregate, tap water, polycarboxylic acid high performance water reducer, rosin air conditioner.

\subsection{Mix proportion}

The mix proportion of 3 kinds of concrete are shown as table 1 .
Table 1. Mix proportion of concrete $\mathrm{kg} / \mathrm{m}^{3}$

\begin{tabular}{|c|c|c|c|c|c|}
\hline $\begin{array}{c}\text { I } \\
\mathrm{D}\end{array}$ & $\begin{array}{c}\text { Cemen } \\
\mathrm{t}\end{array}$ & Fly ash & Water & $\begin{array}{c}\text { San } \\
\mathrm{d}\end{array}$ & $\begin{array}{c}\text { Ston } \\
\mathrm{e}\end{array}$ \\
\hline 1 & 542 & 0 & 220 & 573 & 1065 \\
\hline 2 & 542 & 0 & 220 & 573 & 1065 \\
\hline 3 & 461 & 81 & 220 & 573 & 1065 \\
\hline
\end{tabular}

The air content of No.1 concrete is the nature air content without any rosin air conditioner. No. 2 and No. 3 concrete have the same air content which is adjusted by rosin air conditioner. The slumps of these 3 kinds of concrete are all $(10 \pm 3) \mathrm{cm}$.

\subsection{Specimens}

For each mix proportion, 3 specimens which size is $100 \mathrm{mmx} 100 \mathrm{mmx} 400 \mathrm{~mm}$ has been made for anti-frozen test. The control group specimens for anti-frozen test are also 3 pieces which will be kept in curing room until the treatment group goes to test date.

For micro pore structure test, 3 specimens which size is $100 \mathrm{~mm} \times 100 \mathrm{~mm} \times 100 \mathrm{~mm}$ need to be made. They will be put into the freeze and thaw machine until the recycle is finished. Then crush them and detect its pore structure parameters. There are still 3 cubic specimens which will be kept in the curing room. After recycle finished, they will be crushed as the treatment group and test their pore structure.

\subsection{Test methods}


Put the harden concretes whose mould have been removed after $24 \mathrm{~h}$ into the standard curing room whose temperature is $20{ }^{\circ} \mathrm{C} \pm 2{ }^{\circ} \mathrm{C}$ and relative humidity is $95 \% \pm 3 \%$. After $27 \mathrm{~d}$ curing, put the treatment specimen into fast freeze and thaw test machine. By reference, the fast freeze and thaw cycle test is done as the Standard for Test Methods of Long-term Performance and Durability of Ordinary Concrete [7]. Every 25 times recycle, take the specimen out from freeze-thaw test machine and test the dynamic modulus of elasticity. The control group specimen who is kept in the standard curing room will be test on the same date of treatment group.

After finishing the freeze-thaw recycle, take the cubic specimen out and crush by jaw crusher. Griddle these crushed sand by $4.74 \mathrm{~mm}$ and $2.36 \mathrm{~mm}$ square hole sieve. Select 10 gram particle on the $2.36 \mathrm{~mm}$ sieve. Use ultrasonic washing unit to clean these particle for 5 minute. Put them into oven and dry $24 \mathrm{~h}$ with a temperature of $105^{\circ} \mathrm{C} \pm 5^{\circ} \mathrm{C}$. Take them out and cool at nature environment. And then test the pore structure parameters with Mercury Injection Apparatus.

\section{Test result and date analysis}

The dynamic modulus of elasticity of concrete have detected after every 25 recycles. Micro pore structure data including porosity, average pore size, critical pore size, fractal dimension, percentage composition of pore with different range of size and pore size distribution are all obtained.

\subsection{Analysis of dynamic modulus of elasticity} From Fig. 1 to Fig. 4 shows the changing of dynamic modulus of elasticity for 3 kinds of concrete.

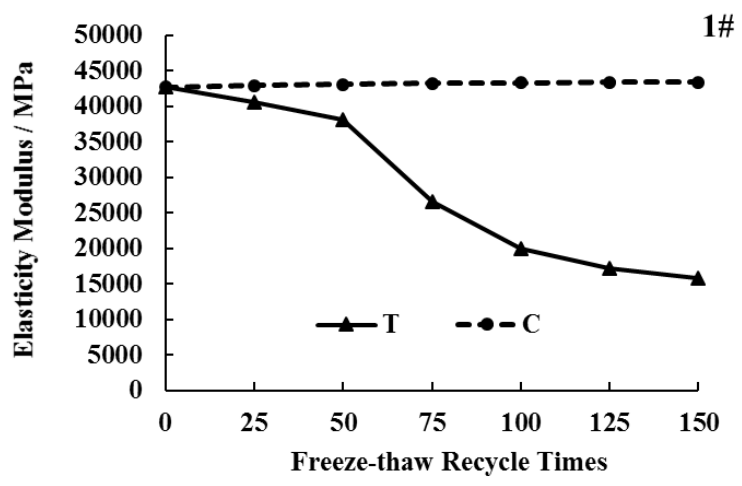

Fig.1. Elasticity modulus VS freeze-thaw recycle times for 1\# Concrete

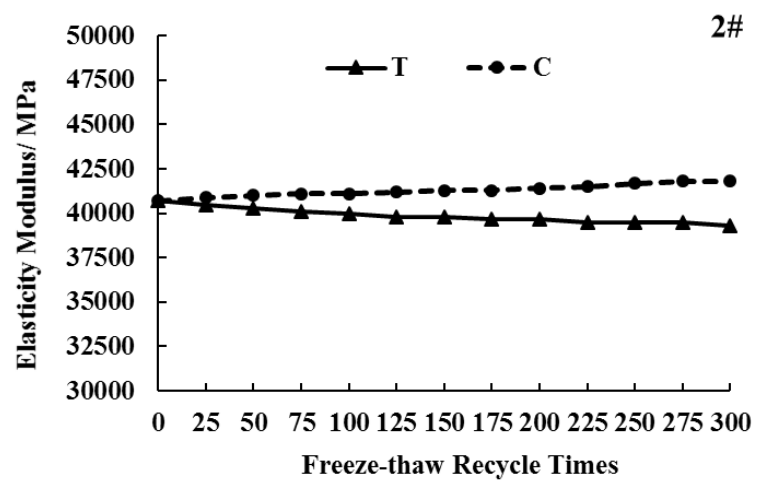

Fig.2. Elasticity modulus VS freeze-thaw recycle times for 2\# Concrete

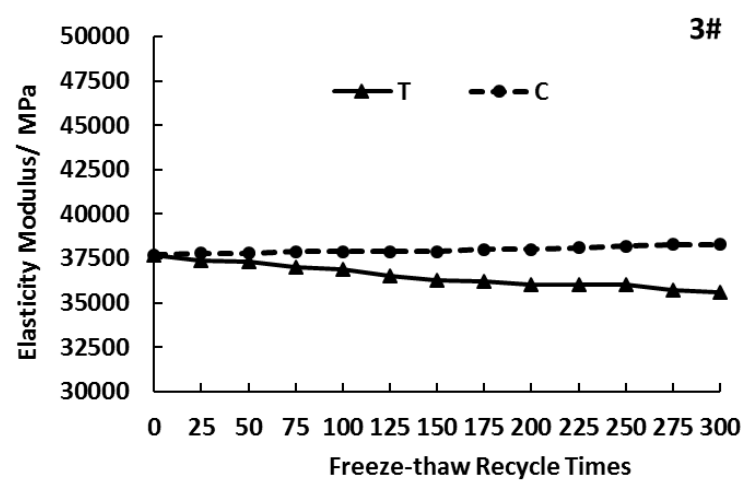

Fig.3. Elasticity modulus VS freeze-thaw recycle times for 3\# Concrete

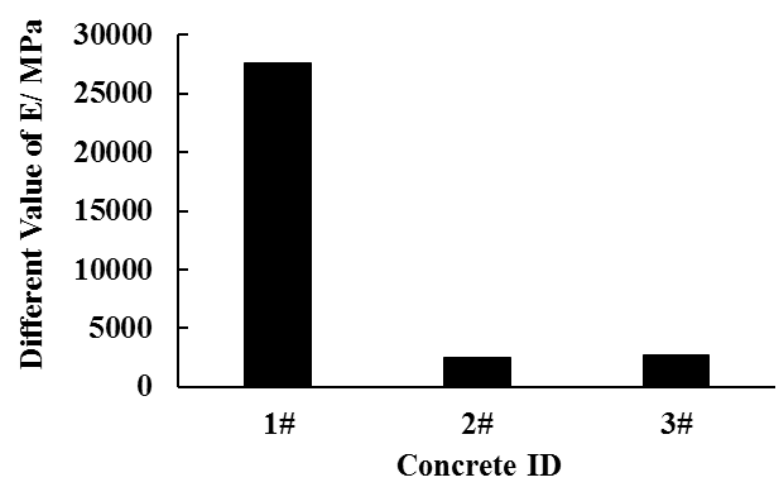

Fig.4. Different value of elasticity modulus at the end of test for 3 kinds of concrete

From Fig. 1, the elasticity modulus of $1 \#$ concrete decrease heavily. Only 150 recycles can make 1\# concrete destroyed. 2\# and 3\# concrete don't be destroyed after 300 recycles. So $2 \#$ and $3 \#$ concrete are better than $1 \#$ concrete on anti-frozen durability.

On the second, 2\# concrete with air entraining agent whose elasticity modulus is $40.7 \mathrm{GPa}$ is larger than $1 \#$ concrete without any air entraining agent. 3\# concrete with fly ash whose modulus is $37.7 \mathrm{GPa}$ is a little lower than 2\# concrete. From Fig. 4, the different value of modulus between $2 \#$ and $3 \#$ concretes are similar. Therefore, the air entraining is the main factor to enhance concrete anti-frozen durability.

\subsection{Analysis of pore structure parameters}


From Fig. 5 to Fig. 8 shoows the change of pore structure parameters before and after freeze-thaw recycle.

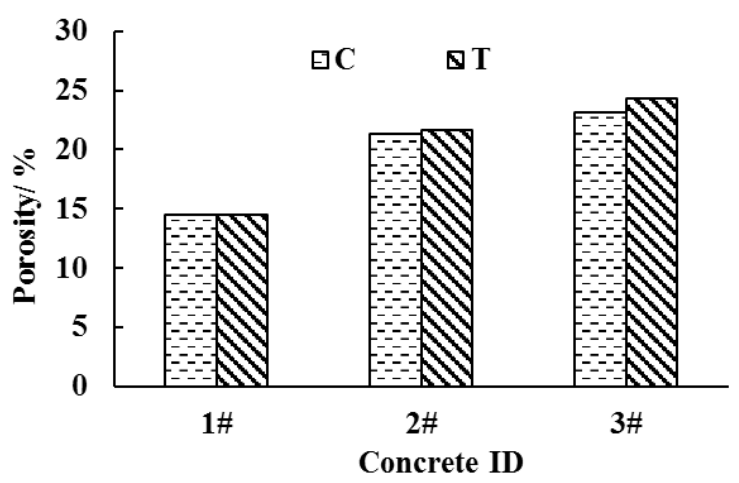

Fig.5. Porosity of different concrete

Porosity is an index to estimate the compactness of concrete. The larger the porosity, the lower the density. Fig. 5 shows that the porosity becomes larger after freeze and thaw recycle. It means freeze and thaw recycle make concrete more porosity.

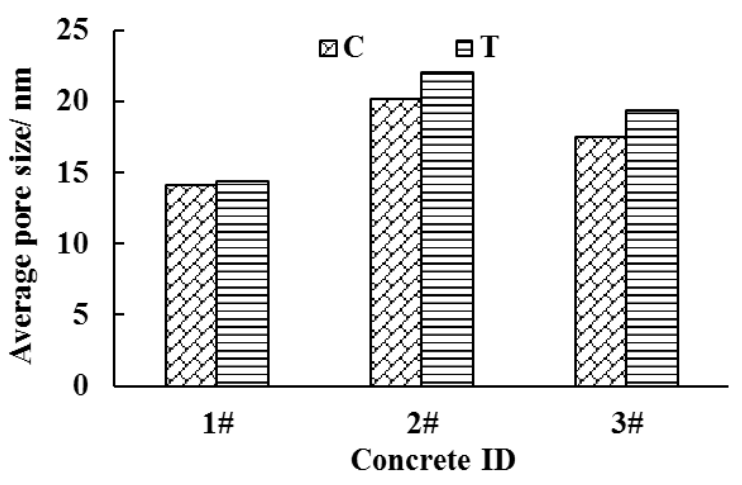

Fig.6. Average pore size of different concrete

Average pore size can estimate the pore size generally. The larger Average pore size, the worse the concrete. From Fig. 6, it can be seen freeze and thaw recycle make concrete worse.

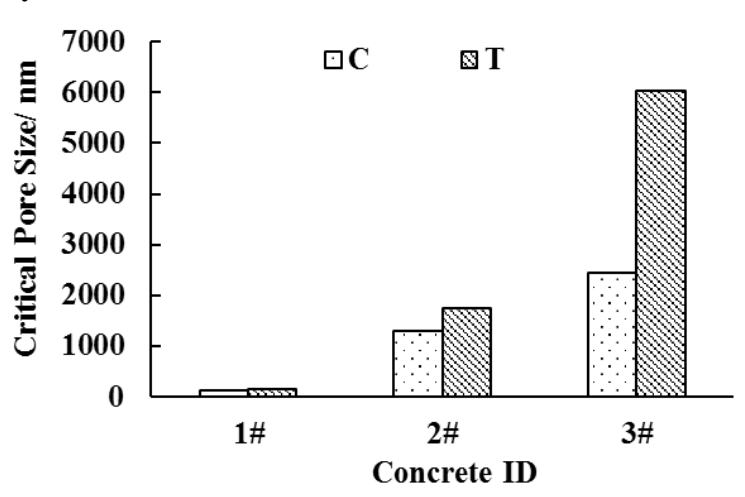

Fig.7. Critical pore size of different concrete

Critical pore can make all range of pore penetrated. The larger the critical pore, the worse the permeability. Fig. 7 shows that freeze and thaw recycle can make critical pore larger. It is harmful to the permeability of concrete.

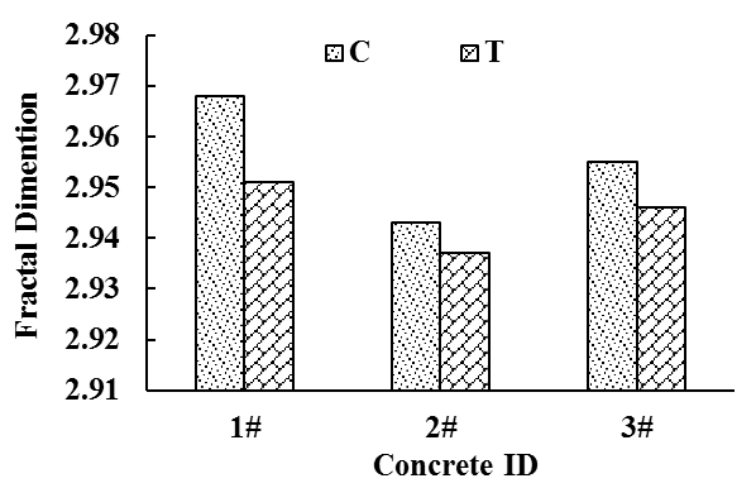

Fig.8. Fractal dimension of different concrete

Fractal dimension can describe the complex of the pore structure of concrete. The larger the fractal dimension, the more complex the outline of pore. Fig. 8 shows that freeze and thaw recycle can make this value smaller. It means that freeze and thaw recycle can make the outline of pore simple.

\subsection{Analysis of pore grading}

Pore can be divided into 4 grading according to I.O Butte. They include gel pore whose pore size is smaller than $10 \mathrm{~nm}$, transitional pore whose pore size is among $10-100 \mathrm{~nm}$, capillary pore whose pore size is among 100$1000 \mathrm{~nm}$ and macro pore whose pore size is larger than $1000 \mathrm{~nm}$. Actually, capillary pore and macro pore are harmful to concrete. From Fig. 9 to Fig. 12 shows the difference of these pores before and after freeze and thaw recycle.

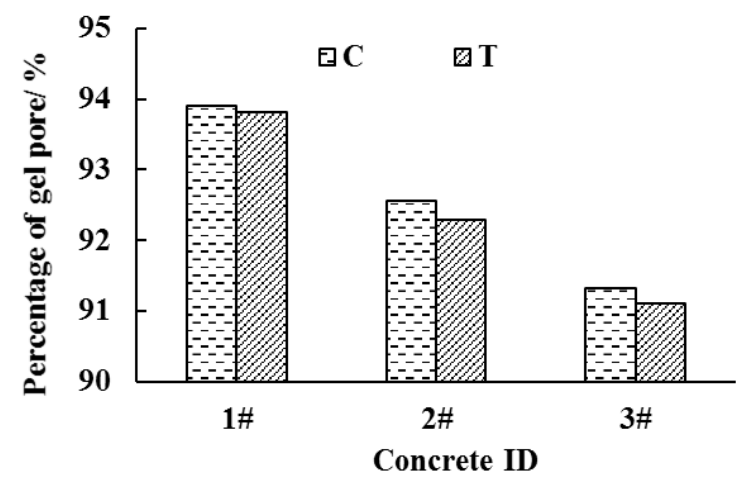

Fig.9. Percentage of gel pore of different concrete

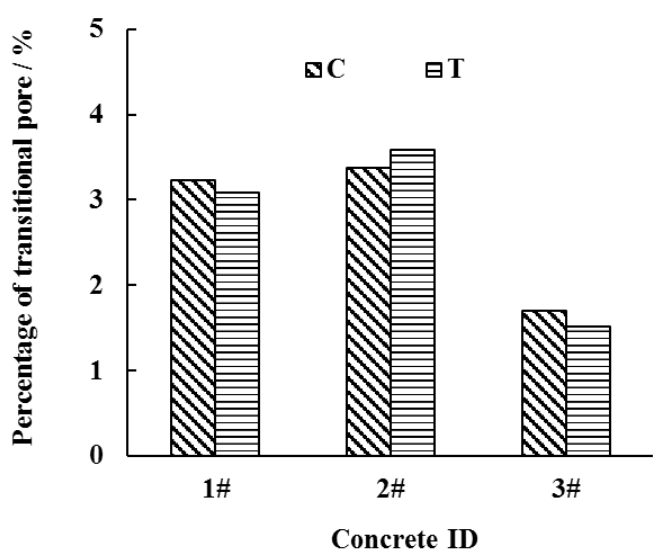


Fig.10. Percentage of transitional pore of different concrete

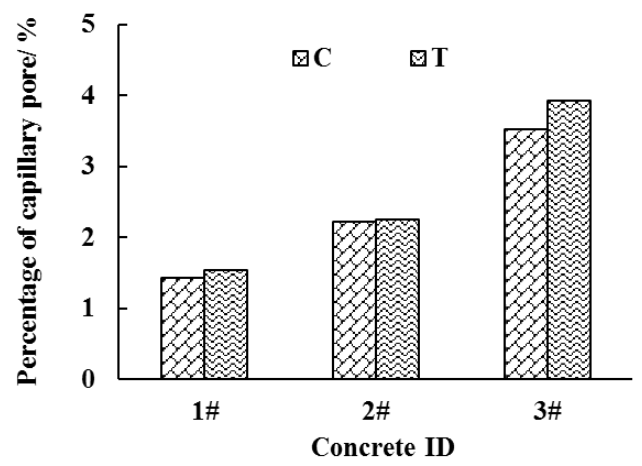

Fig.11. Percentage of capillary pore of different concrete

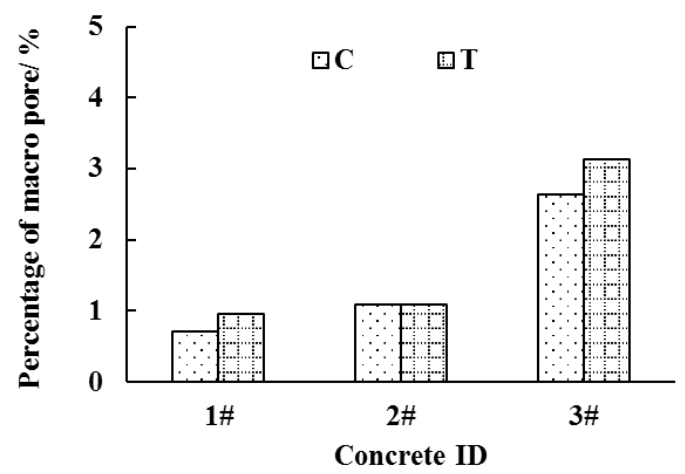

Fig.12. Percentage of macro pore of different concrete

From Fig. 9, Fig. 11 and Fig. 12, freeze and thaw recycle decrease the amount of gel pore but increase the amount of capillary and macro pore. These changing are harmful to concrete.

Fig. 10 shows that the amount of transitional pore of 2\# concrete becomes larger after freeze and thaw recycle. The amount of transitional pore of $1 \#$ and $3 \#$ concrete are fewer than before. It is because that $3 \#$ concrete has fly ash in it and is denser than $2 \#$ concrete.

Therefore, 2\# and 3\# concrete are better than 1\# because the air entrained and fly ash addition.

\subsection{Pore distribution}

Fig. 13 is the pore distribution curve. It shows that the curves of $1 \#$ concrete move towards the macro pore size direction.

For 2\# and 3\# concrete, pore distribution curve move towards micro pore size direction.

From pore distribution figure, it can be seen that the amount of pores in 2\# and 3\# concrete whose size is among $100 \mathrm{~nm}-1000 \mathrm{~nm}$ become larger than the ones which haven't air entrained.

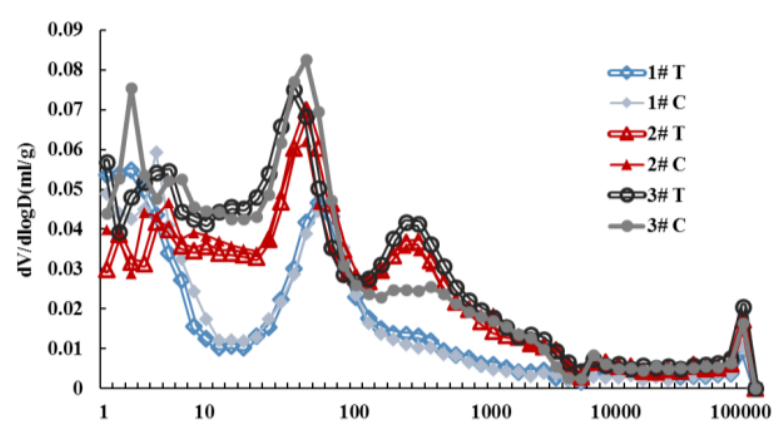

Fig.13. Pore size distribution

\subsection{Relationship between Elasticity modulus and pore structure}

The trends of changing of elasticity modulus and pore structure indexes are listed as table 2 .

Table 2. List of macro and micro indexes after frozen

\begin{tabular}{|c|c|c|}
\hline Index & Changing trend & Relativity with E \\
\hline Modulus & $\downarrow$ & $/$ \\
\hline Porosity & $\uparrow$ & negative \\
\hline Average pore size & $\uparrow$ & negative \\
\hline Critical pore size & $\uparrow$ & negative \\
\hline Fraction dimension & $\downarrow$ & positive \\
\hline Gel pore content & $\downarrow$ & positive \\
\hline $\begin{array}{c}\text { Capillary pore } \\
\text { content }\end{array}$ & $\uparrow$ & negative \\
\hline Macro pore content & $\uparrow$ & negative \\
\hline
\end{tabular}

Elasticity modulus can reflect the anti-frozen durability of concrete and can be detected without destroy the specimen.

From table 2, in order to enhance the anti-frozen durability of concrete, decrease the porosity, average pore size, average pore size and critical pore size or you can increase the friction dimension of concrete. What's more, increase the content of gel pore and decrease the capillary and macro pores.

\section{Conclusions}

To detect which micro structure index can make an effected on the anti-frozen durability on concrete, 3 kinds of concrete with different mix proportion have been made. The dynamic modulus of elasticity and pore structure index were detected and the relativity of them was analysed. The result can be concluded as follow.

(1) Freeze and thaw recycle can make concrete modulus decrease especially for concrete without air entrained. For air entrained concrete, the anti-frozen durability is much better than ones without air entrained.

(2) Porosity and average pore size of concrete become larger after frozen. The concrete will become less dense than before. The critical pore size will become larger so that the anti-permeability becomes worse than before. Fraction dimension become less so that the outline of pore become simple. 
(3) Freeze and thaw recycle decrease the percentage of gel pore; increase the percentage of capillary pore and macro pore. The amount of macro pores is more and micro pores is less. The denser the concrete, the less the transition pores after frozen.

(4) After freeze and thaw recycle, pore distribution curve move towards macro pore direction. Air entrained can enlarge the amount of pores among $100 \mathrm{~nm}$ to $1000 \mathrm{~nm}$.

(5) By decreasing the porosity, average pore size and critical pore size, increasing fraction dimension, the anti-frozen durability of concrete can be enhanced. By increasing the content of gel pore and decreasing the content of capillary and macro pore, the antifrozen durability of concrete can also be enhanced. China Highway Natural Division

\section{Acknowledgement}

This work was supported by the Basic Research Found for National Public Welfare Scientific Research Institutions [grant numbers 2017-9004].

\section{References}

1. JTJ 003-1986. China Highway Natural Division. 1987-1-1 implement. (In Chinese)

2. W.ping Yang. Effect of inorganic salts on pore structure and frost resistance of concrete. (Doctor Degree of Harbin University of Technology,2009) (In Chinese)

3. S.Ping Zhang, M. Deng, M.Hu TANG. Journal of Materials Science and Engineering. 26,5(2008). (In Chinese)

4. R.Mu, N.Jiao, F.Fen Jiao. Concrete.7,4( 2016). (In Chinese)

5. Valenza J J, Scherer G W. Cement and Concrete Research. 37,14(2007): 1007-1021.

6. L. Yu. Study on durability of cement concrete in multi erosion. (Doctor Degree of Beijing University of Technology, 2013) (In Chinese)

7. GB/T 50082-2009. Standard for Test Methods of Long-term Performance and Durability of Ordinary Concrete. (In Chinese) 